\title{
Internet of Things in Agriculture: A Primer
}

\section{Matthew N. O. Sadiku1 ${ }^{*}$, Tolulope J. Ashaolu², Abayomi Ajayi-Majebi ${ }^{3}$ and Sarhan M. Musa ${ }^{1}$}

\author{
${ }^{1}$ Roy G. Perry College of Engineering, Prairie View A\&M University, Prairie View, TX, USA \\ ${ }^{2}$ College of Food Science, Southwest University, Beibei, Chongqing, China
}

${ }^{3}$ Department of Manufacturing Engineering, Central State University,Wilberforce, $\mathrm{OH}$, USA

Email: sadiku@ieee.org; ashaolut@gmail.com; ajayi-majebi@centralstate.edu; smmusa@pvamu.edu

\author{
*Corresponding author details: Prof. Matthew N. O. Sadiku; anthonymaccini@hotmail.com
}

\begin{abstract}
To meet the growing food demand, agricultural businesses are turning to the Internet of things for analytics and greater production capabilities. The Internet of things (IoT) is essentially making "dumb" things "smart" by connecting them to each other and to the Internet. Farmers are turning to IoT solutions to increase efficiencies and yields and reduce loss and waste. In an agricultural context, IoT refers to the use of sensors, cameras, and other devices to turn every element and action involved in farming into data. IoT is poised to push the future of agriculture to the next level. In this paper, we will explore various applications of IoT in agriculture and examine their benefits and challenges.
\end{abstract}

Keywords: internet of things; agriculture; smart farming; precision agriculture

\section{INTRODUCTION}

Agriculture is a big business. It is a form of manufacturing heavily capital intensive. It plays a vital role in any nation's economy. Today's agricultural businesses must contend with issues like population growth, workforce impact from pandemics, financial upheaval, unpredictable climate conditions, increasing water shortages, shrinking arable land, limited availability of natural resources, and fluctuating costs. To accommodate the needs of the growing population, the agriculture industry needs to adopt new technologies. The demand can be successfully met with IoT. IoT applications are focused on helping farmers close the food supply demand gap by ensuring high yields, profitability, and protection of the environment.

The Internet of things (IoT) allows all entities to be connected to each other through wired or wireless communication means. IoT means physical devices are connected so that they can send and receive information via the Internet. IoT has been gaining popularity rapidly since its inception into the IT world and is being used in healthcare, education, gaming, finance, transportation, agriculture, etc. [1]. Agriculture employs IoT through the use of robots, drones, sensors, and computer imaging Various innovative uses of IoT applications in agriculture are driving opportunities for increase yields while improving food safety and delivery.

\section{OVERVIEW ON INTERNET OF THINGS}

Internet of things (IoT) is a worldwide network that connects devices to the Internet and to each other using wired or wireless technology. IoT is expanding rapidly and it has been estimated that 50 billion devices will be connected to the Internet by 2020 . These include smart phones, tablets, desktop computers, autonomous vehicles, refrigerators, toasters, thermostats, cameras, pet monitors, alarm systems, home appliances, insulin pumps, industrial machines, intelligent wheelchairs, wireless sensors, mobile robots, etc.

There are four main technologies that enable IoT [2]:

1) Radio-frequency identification (RFID) and near-field communication.

2) Optical tags and quick response codes; this is used for low cost tagging.

3) Bluetooth low energy (BLE).

4) Wireless sensor network.

Other related technologies are cloud computing, machine learning, and big data.

The Internet of things (IoT) technology enables people and objects to interact with each other. It is employed in many areas such as smart transportation, smart cities, smart energy, emergency services, healthcare, data security, industrial control, logistics, retails, structural health, traffic congestion, manufacturing, industry, security, agriculture, environment, and waste management.

IoT supports many input-output devices such as camera, microphone, keyboard, speaker, displays, microcontrollers, and transceivers. It is the most promising trend in the healthcare industry. This rapidly proliferating collection of Internet-connected devices has the potential to connect patients and their providers in a unique way. As IoT depends on sensor massive data collections to be able predict accurate results [3]. 
The narrowband version of IoT is known as narrowband IoT (NBIoT). This is an attractive technology for many sectors because it has been standardized [4]. The main feature of NBIoT is that it can be easily deployed within the current cellular infrastructure with a software upgrade.

IoT has found several applications in transportation, environmental monitoring, forecasting, agriculture, healthcare, security, and energy conservation IoT in agriculture uses robots, drones, remote sensors, and computer imaging combined with continuously progressing machine learning and analytical tools for monitoring crops. To ensure food safety, data-driven solutions enabled by the Internet of Things will allow consumers to track and monitor produce from farm to fork.

\section{INDUSTRIAL INTERNET OF THINGS (IOT)}

While the IoT affects among others transportation, healthcare, or smart homes, the Industrial Internet of Things (IIoT) refers in particular to industrial environments. IIoT is a new industrial ecosystem that combines intelligent and autonomous machines, advanced predictive analytics, and machine-human collaboration to improve productivity, efficiency and reliability. It is bringing about a world where smart, connected embedded systems and products operate as part of larger systems.

IIoT is often used in the context of Industry 4.0, the Industrial Internet and related initiatives across the globe. Industry 4.0 describes a new industrial revolution with a focus on automation, innovation, data, cyber-physical systems, processes, and people. With Industry 4.0, the fourth industrial revolution is set on merging automation and information domains into the industrial Internet of things, services, and people. The communication infrastructure of Industry 4.0 allows devices to be accessible in barrier-free manner in the industrial Internet of things, without sacrificing safety and security [5].

The industrial Internet of things (IIoT) refers to the application of the Internet of things (IoT) across several industries such as manufacturing, logistics, oil and gas, transportation, energy/utilities, chemical, agriculture, and other industrial sectors. IIoT has been a driving force behind increased agricultural production at a lower cost. The introduction of IIoT in agriculture involves using more advanced sensors in every step of the farming process.

\section{APPLICATIONS}

Internet of things has brought huge benefits like efficient use of water, optimization of inputs and many more. IoT applications in agriculture include livestock monitoring, smart farming, precision farming, smart greenhouses, agricultural drones. These applications are illustrated in FIGURE 1 [6] and discussed as follows $[7,8]$

\section{- Smart Farming}

Smart farming refers to the adoption of information and communications technologies to enhance and automate agricultural processes and operations. It is a farming management concept that involves using modern technology to increase the quantity and quality of agricultural products. It is a capital-intensive and hi-tech system of growing food cleanly and sustainable for the masses. It is essentially the application of modern ICT (information and communication technologies) into agriculture. IoT-based smart farming can monitor the agricultural land with the help of sensors. It enables growers and farmers to reduce waste and enhance productivity. It depends largely on IoT thereby eliminating the need of physical work of farmers. IoT based smart farming improves the entire agriculture system by monitoring the field in real-time and provide more efficient water usage.
It helps farmers improve yields by increasing productivity and operational efficiency [9]. Smart farming has two components: (1) AgriTech, which is a software that is created for the improvement of some farming processes; (2) Smart agriculture, which refers to the application of the IoT and various devices connected to each other.

\section{- Smart Greenhouses}

Greenhouse farming may be regarded as the oldest form of smart farming. It helps in enhancing the yield of vegetables, fruits, crops, etc. Traditionally, farmers use manual intervention to control the greenhouse environment. Manual intervention results in production loss, energy loss, and labor costs. A smart greenhouse is designed with the help of IoT to intelligently monitor and control the climate, eliminating the need for manual intervention. It leverages the IoT-connected devices to create a self-regulating microclimate conducive to crop production. The IoT sensors in the greenhouse provide accurate real-time information about the greenhouse conditions such as lighting, soil condition, pressure, humidity, and temperature.

\section{- Smart Irrigation}

The irrigation sector has undergone a remarkable transformation in recent decades due to the application of pressurized water distribution technologies. Insufficient and excessive levels of water can harm plants. The traditional irrigation system is under pressure due to the growing water shortages, which are mainly caused by population growth and climate change. The control of water resources to increase the allocation of retained water is important. IoT-equipped irrigation systems conserve water and ensure that crops are getting just the right amount of water. IoT solutions provide just the right amount of irrigation and when they should be irrigating [10].

\section{- Precision Farming}

This is also known as precision agriculture. It can be regarded of as anything that makes farming practice more controlled and accurate. It is the most common application of IoT in the agricultural sector. It is about providing more accurate farming techniques for planting and growing crops. It is the use of information and communication technology (ICT) along with best agricultural practices. It may boost agricultural production while reducing harmful impact on the environment. It can make a big difference to food production facing the challenge of a rising world population. Precision agriculture provides farmers with such concrete information that enables them to make informed decisions. In precision agriculture, drones are used in various ways from soil and crop field analysis to planting and pesticide spraying [11].

\section{- Agricultural Drones}

Agriculture is one of the major industries to incorporate drones in order to enhance various agricultural practices. Also known as unmanned aerial vehicles (UAVs), drones are better equipped than airplanes and satellites to collect agricultural data. Drones are being used in agriculture to enhance various agricultural practices: crop health assessment, irrigation, crop monitoring, crop spraying, planting, and soil and field analysis. They have become an invaluable tool for farmers to survey their lands, perform field analysis, and generate real-time data. Drones can spray fertilizer 40 times faster than doing it manually. FIGURE 2 shows a typical agriculture drone [12].

\section{- Livestock Monitoring}

Farm productivity depends on keeping crops and livestock healthy around the clock. IoT solutions can help farmers to collect data regarding the location, well-being, and health of their cattle. They can help farmers monitor with innovative solutions that lead to actionable and data-driven insights. 
IoT devices support crop and livestock health through sensor-based monitoring and alerts. Wireless IoT can be used to collect data regarding the location, well-being, and health of their cattle. Farmers can use their smartphones to remotely monitor their equipment, crops, and livestock. FIGURE 3 depicts livestock monitoring [13]

\section{- Weather Forecasting}

Weather is a paramount factor in agriculture industry. Forecasting and monitoring of weather conditions empower farmers with information that can guide them during planting, harvesting, and other related activities. Therefore, weather condition must be accurately predicted so as to carry out production activities. Weather forecasting can be done through analysis of weather data over long periods. Temperature, humidity, light intensity, and soil moisture can be monitored through various sensors [14]

Other applications of IoT in agriculture include connected farming, autonomous farm vehicles, agricultural drones, crop management, predictive analytics, asset tracking, smart waste management, and crop management.

\section{BENEFITS}

Utilizing the IoT in agriculture is undeniably the smartest way to feed humanity. IoT has brought huge benefits like efficient use of water, optimization of inputs, decrease in costs, increase in yields, and improve farmer's decision making with accurate data. It can make agricultural processes more efficient by reducing human intervention through automation.

It has also reduced the wasteful use of resources such as water and electricity. Agriculture IoT has a unique opportunity to build connected agricultural solutions that can lead to improved yields, reduced costs, and a well-fed world.

Other benefits of adopting Internet of things in agriculture include [12]:

- Data collected by smart agriculture sensors can be used to track the state of your business.

- Better control over the internal processes and lower production risks.

- Cost management and waste reduction

- Increased business efficiency through process automation

- Enhanced product quality and volumes

- Reduction of risks

- Products of high quality

- High adoption costs

- Improvement in use efficiency of inputs (soil, water, fertilizers, pesticides, etc,)

- Reduced cost of production

- Protection of the environment

\section{CHALLENGES}

Positioning the sensor for an optimal communication path is an engineering challenge. Other Challenges that slow the mass adoption of IoT in agriculture include [15].

- High capital investment is needed to implement and maintain IoT systems

- Poor coverage and connectivity in rural areas across the globe

- Data security breaches and privacy

- IoT devices are easy to hack and compromise

- Fragmented market of small individual players

- Increased cybersecurity risk

- Analyze large scale unstructured data

- Crop management

- Fear of new technology

- Technology is in its infancy

- Fear of new technology

Some of these challenges are illustrated in FIGURE 4 [16].
GLOBAL AGRICULTURE IOT

The global agriculture IoT market is mainly segmented on the basis of component (hardware, software, services), application (precision farming, smart greenhouse, livestock monitoring, smart irrigation, etc.), and geography. The hardware segment commanded the largest share of the overall agriculture IoT market in 2020. The precision farming segment accounted for the largest share of the overall agriculture IoT market in 2020. North America commanded the largest share of the global agriculture IoT market in 2020. The global agriculture IoT market is dominated by few major players: Deere and Company (US), Trimble Inc. (US), AGCO Corporation (US), Raven Industries (US), AgJunction (US), Delaval (Sweden), GEA Group (Germany), Antelliq (France), Ponsse (Finland), and Komatsu Forest (Sweden) [17]. We now consider how IoT is applied in agriculture around the world.

\section{- United States}

JMB North America has brought to market an IoT solution that helps ranchers monitor pregnant cows that are preparing to give birth. John Deere has developed a leading approach to precision agriculture technology through advanced communications and telematics. Through US and Canadian facilities, John Deere markets products to approximately 1,981 dealer locations. Outside the US and Canada, John Deere agriculture and turf equipment is sold to distributors and dealers for resale in over 100 countries.

\section{- Europe}

European farmers are already using smart agriculture technologies such as yield monitoring, GNSS technology in guidance and steering, variable rate application, and crop scouting. In Europe, large-scale deployments (LSPs) of IoT will be funded by the European Commission. The objective of an LSP is to evaluate the usability and usefulness of IoT technologies in agriculture, The European Research and Innovation agenda includes deployment of IoT to meet the real needs of public authorities, citizens, and business [18]. The adoption rate of animal tracking, dairy cattle management, and other livestock monitoring technologies is high in Germany.

\section{- United Kingdom}

The UK is focusing on changing its agriculture IoT landscape by entering into the new era of technological developments to meet the rising demand for food by a growing population, rapid changes in climate, changing diets, and increasing scarcity of natural resources.

\section{- India}

In India, about 58 percent of the population relies on agriculture for their livelihood and one-third of the nation's capital comes from agriculture. However, crop diseases are one of many hurdles' farmers have to continually deal with. Change of climate affects the agricultural crops production significantly. One approach farmer take in the Indian State of Punjab is fighting these diseases through the data collected by IoT-enabled remote sensors. The implementation of IoT in agriculture poses some own unique challenges in India, especially for farmers who have small land-holding and are located in rural areas. By monitoring conditions such as humidity, rainfall and temperature levels, farmers are able to better determine their crops susceptibility. With India's population now surpassing a whopping 1.2 billion people, smart farming IoT solutions promise to provide greater food-security and optimize yield for this largely agrarian economy. Data Quest India reported that there is potential for IoT-based applications to have a transformational impact with regards to rural job creation [19]. 


\section{- Canada}

MotorLeaf from Canada is one of the leading companies in the development of agricultural technology. MotorLeaf is a platform that uses IoT in agriculture to manage the yield and quality of crops. They produce automatic greenhouse technologies made possible by artificial intelligence. This technology allows farmers to make data-driven decisions about how to best grow their crops. The technology has been produced especially for hydroponic greenhouses. Hydroponics has advantages in many respects compared to soiled agriculture. Soilless greenhouse does not require fertilization, spraying, and over-irrigation technology.

\section{- Thailand}

This nation has a plan to develop the country with innovation under the Thailand 4.0 policy and new technology for Thai agriculture. Most Thai farmers grow and export rice for the global market. However, farmers lack knowledge and innovation that is necessary to control the environment Therefore, there is the need to develop a prototype for a smart farm system to support local Thai farmers.

\section{CONCLUSION}

There is real momentum behind IoT technology in agriculture and farming. Farmers have realized that the IoT is a driving force for increasing agricultural production in a cost-effective way. From farm to fork, IoT technologies can transform agriculture sector by contributing to food safety and reducing food waste. IoT applications are enabling farmers to collect data that is essential to maintain better farm practices and enhance their business's growth. More information on IoT in agriculture or farming can be found in the book in [20-26] and a related journal:Journal of Advanced Agricultural Technologies.

\section{REFERENCES}

[1] M. N. O. Sadiku, S. Alam, and S.M. Musa, "IoT for healthcare," International Journal of Electronics and Communication Engineering, vol. 5. no. 11, November 2018, pp. 5-7.

[2] M.N.O. Sadiku, and S.M. Musa and S. R. Nelatury, "Internet of things: An introduction," International Journal of Engineering Research and Advanced Technology, vol. 2, no.3, March 2016, pp. 39-43.

[3] C. E. A. Zaouiat and A. Latif, "Internet of things and machine learning convergence: The e-healthcare revolution," Proceedings of the 2nd International Conference on Computing and Wireless Communication Systems, Larache, Morocco, November 2017.

[4] S. Anand and S. K. Routray, "Issues and challenges in healthcare narrowband IoT," International Conference on Inventive Communication and Computational Technologies, 2017, pp.486-489.

[5] M. N. O. Sadiku, Y. Wang, S. Cui, and S. M. Musa "Industrial Internet of things," International Journal of Advances in Scientific Research and Engineering, vol. 3, no. 11, Dec. 2017, pp. 1-4.

[6] R. K. Saini and C. Prakash, "Internet of things (IoT) for agriculture growth using wireless sensor networks," Global Journal of Computer Science and Technology: E Network, Web \& Security, vol. 20, no. 2, Version 1.0, 2020.

[7] S. Ravindra, "IoT applications in agriculture," June 2020, https://www.iotforall.com/iot-applications-inagriculture

[8] " $5 \mathrm{G}$ and smart farming IoT -Promise of making the world green again," July 2018, Unknown Source.
[9] M. N. O. Sadiku, T. J. Ashaolu, A. Ajayi-Majebi, and S. M. Musa, "Smart Farming," International Journal of Scientific Advances, vol. 1, no. 3, Nov.- Dec., 2020, pp. 133-134.

[10] J. A. López-Morales, J. A. Martínez, and A. F. Skarmeta, "Improving energy efficiency of irrigation wells by using an IoT-based platform," Electronics, vol. 10, 2021.

[11] M. N. O. Sadiku, Y. Wang, S. Cui, S. M. Musa, "Precision agriculture: An Introduction," International Journal of Advanced Engineering and Technology, vol. 2, no. 2, May 2018, pp. 31-32.

[12] A. Chalimov, "IoT in agriculture: 8 technology use cases for smart farming and challenges to consider," July 2020 https://easternpeak.com/blog/iot-in-agriculturetechnology-use-cases-for-smart-farming-andchallenges-to-consider/

[13] "IoT applications in agriculture - 4 Best benefits of IoT in agriculture," https://data-flair.training/blogs/iotapplications-in-agriculture/

[14] F. O. Bamigboye and E. O. Ademola, "Internet of things (Iot): It's application for sustainable agricultural productivity in Nigeria," Proceedings of the iSTEAMS Multidisciplinary Cross-Border Conference University of Professional Studies, Accra Ghana 2016, pp. 309-312.

[15] "IoT in agriculture: Connected farming is the smarter way to sustainability," January 2021, https://www.intellias.com/iot-agriculture-connectedfarming/

[16] M. Ayaz, "Internet-of-Things (IoT) based smart agriculture: Towards making the fields talk." IEEE Access, vol. XX, 2019.

[17] "Agriculture IoT market worth $\$ 32.75$ billion by 2027 Market size, share, forecasts,

\& trends analysis report with COVID-19 impact by Meticulous Research," March 2021, https://www.globenewswire.com/newsrelease/2021/03/22/2196690/0/en/Agriculture-IoTMarket-Worth-32-75-Billion-by-2027-Market-SizeShare-Forecasts-Trends-Analysis-Report-with-COVID19-Impact-by-Meticulous-Research.html

[18] C. Brewster et al., "IoT in agriculture: Designing a Europe-wide large-scale pilot," http://cbrewster.com/papers/Brewster_CM17.pdf

[19] K. J. Vanaja et al., "IOT based agriculture system using NodeMCU," International Research Journal of Engineering and Technology, vol. 5, no.3, March 2018, pp. 3025-3028.

[20] P. K. Pattnaik, R. Kumar, and S. Pal (eds.), Internet of Things and Analytics for Agriculture, Volume 2. Springer, 2020.

[21] B. Singh, Precision Farming and Protected Cultivation. New Delhi, India: New India Publishing Agency, 2019.

[22] A. Castrignano et al. (eds.), Agricultural Internet of Things and Decision Support for Precision Smart Farming. Academic Press, 2020.

[23] P. Bhattacharyya, H. Pathak, and S. Pal, Climate Smart Agriculture. Springer, 2020 
[24] G. S. Patel et al. (eds.), Smart Agriculture: Emerging Pedagogies of Deep Learning, Machine Learning and Internet of Things. Boca Raton, FL: CRC Press, 2021.

[25] Q. Zhang (ed.), Precision Agriculture Technology for Crop Farming. Boca Raton, FL: CRC Press, 2016.

[26] L. Jupp, Precision Farming from Above. Writing Matters Publishing, 2018.

\section{ABOUT THE AUTHORS}

Matthew N.0. Sadiku is a professor emeritus in the Department of Electrical and Computer Engineering at Prairie View A\&M University, Prairie View, Texas. He is the author of several books and papers. His areas of research interests include computational electromagnetics and computer networks. He is a fellow of IEEE.
Tolulope J. Ashaolu works at Southwest University. He is the author of several papers and two books. His research interests include functional foods and food microbiology.

Abayomi Ajayi-Majebi is a professor in the Department of Manufacturing Engineering at Central State University in Wilberforce, Ohio. In 2015 he was honored by the White House as a Champion of Change for his significant contributions to the engineering education of minority students. He is a senior member of both the Society of Manufacturing Engineers and the American Society for Quality.

Sarhan M. Musa is a professor in the Department of Electrical and Computer Engineering at Prairie View A\&M University, Prairie View, Texas. He has been the director of Prairie View Networking Academy, Texas, since 2004. He is an LTD Sprint and Boeing Welliver Fellow. His areas of research interests include computationalelectromagnetics and computer networks

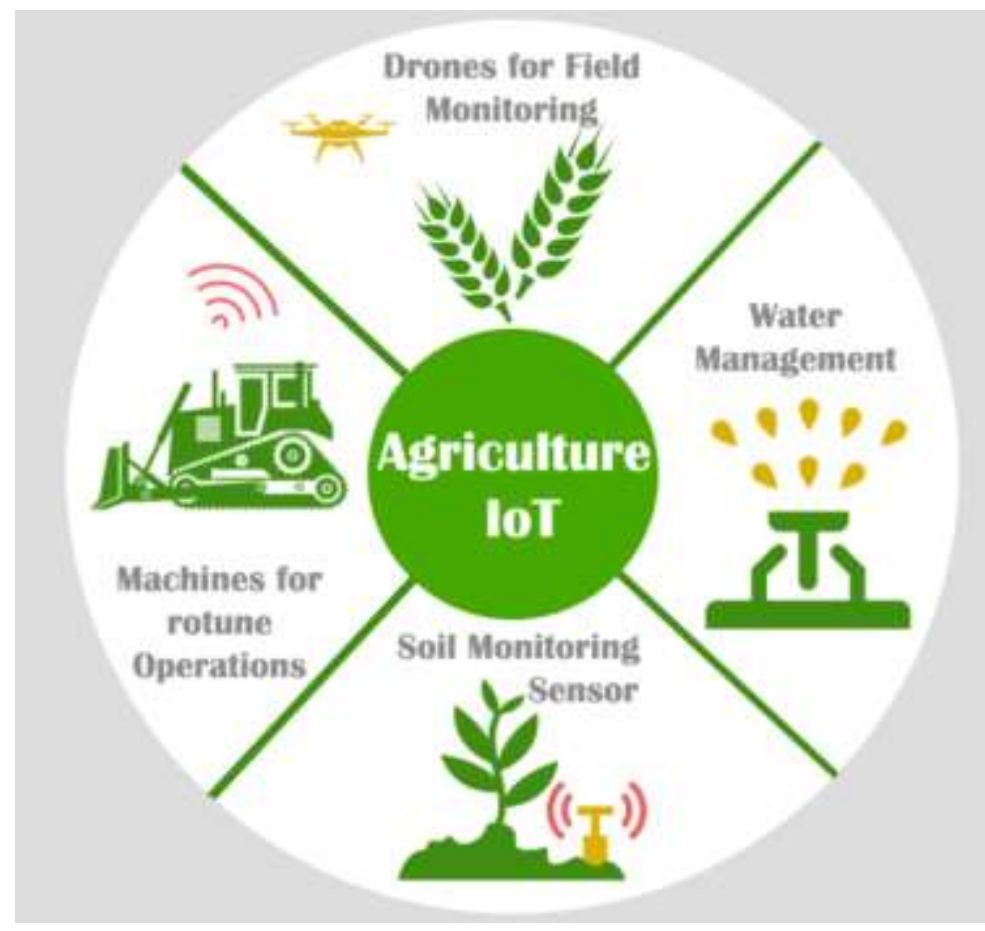

FIGURE 1: Internet of things applications in agriculture [6].

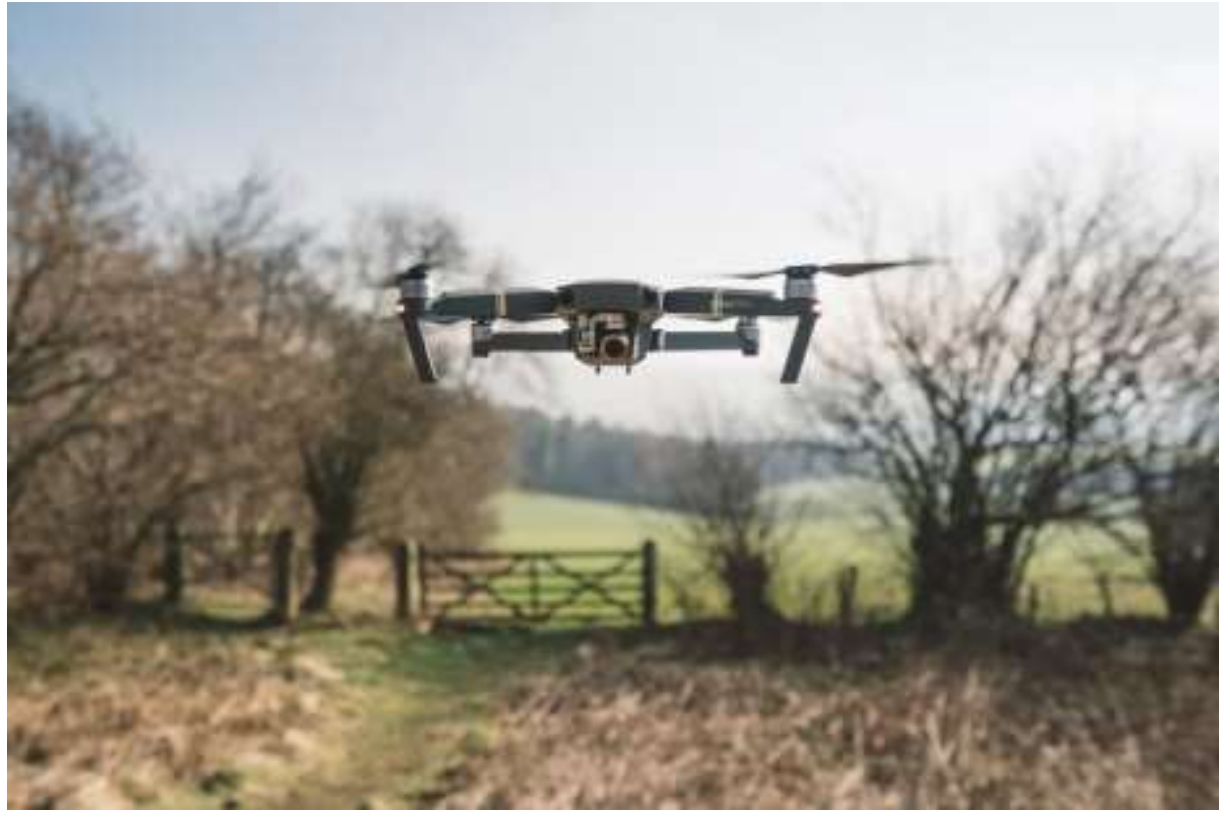

FIGURE 2: A typical agriculture drone [12]. 


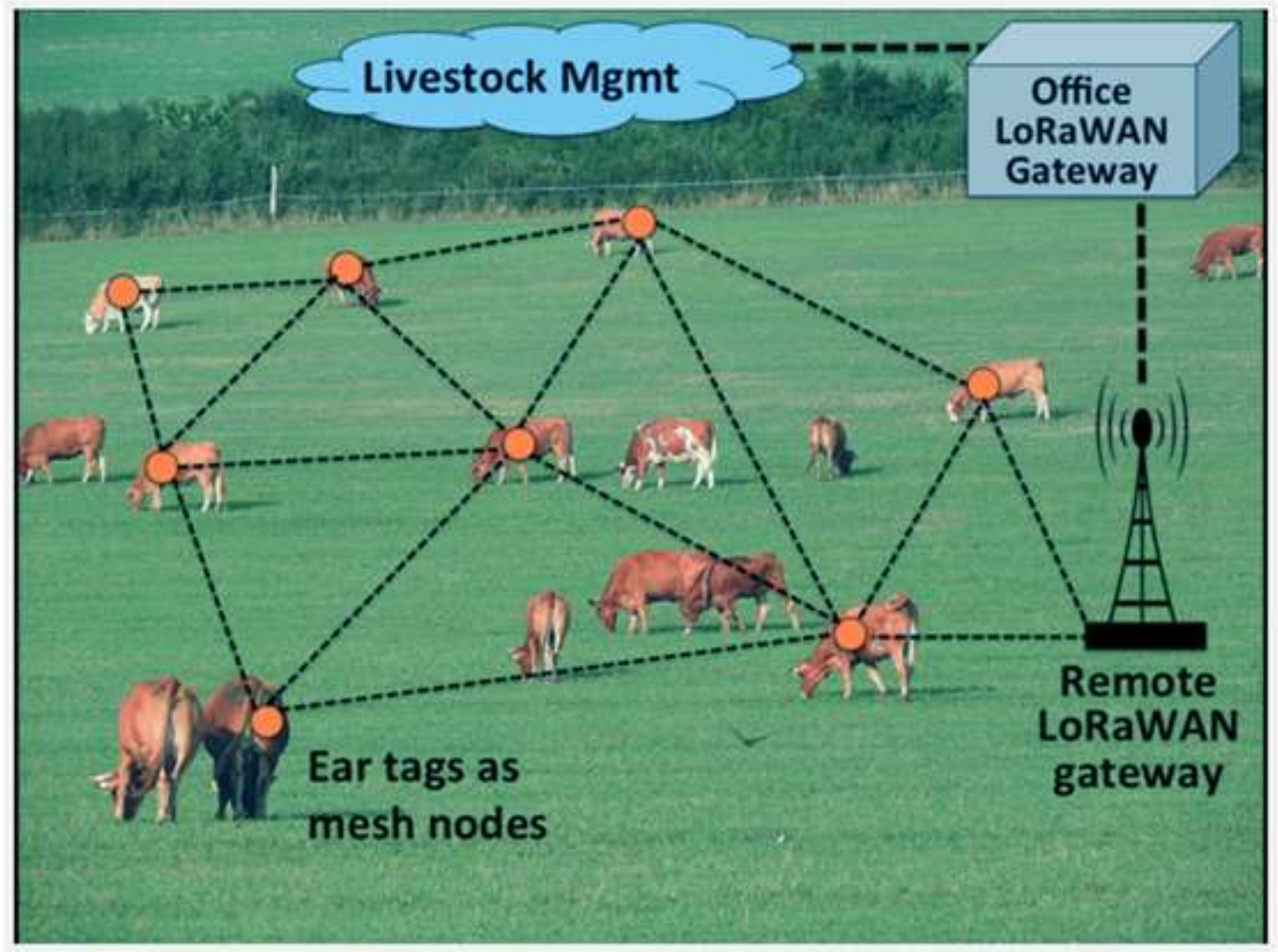

FIGURE 3: Livestock monitoring [13].

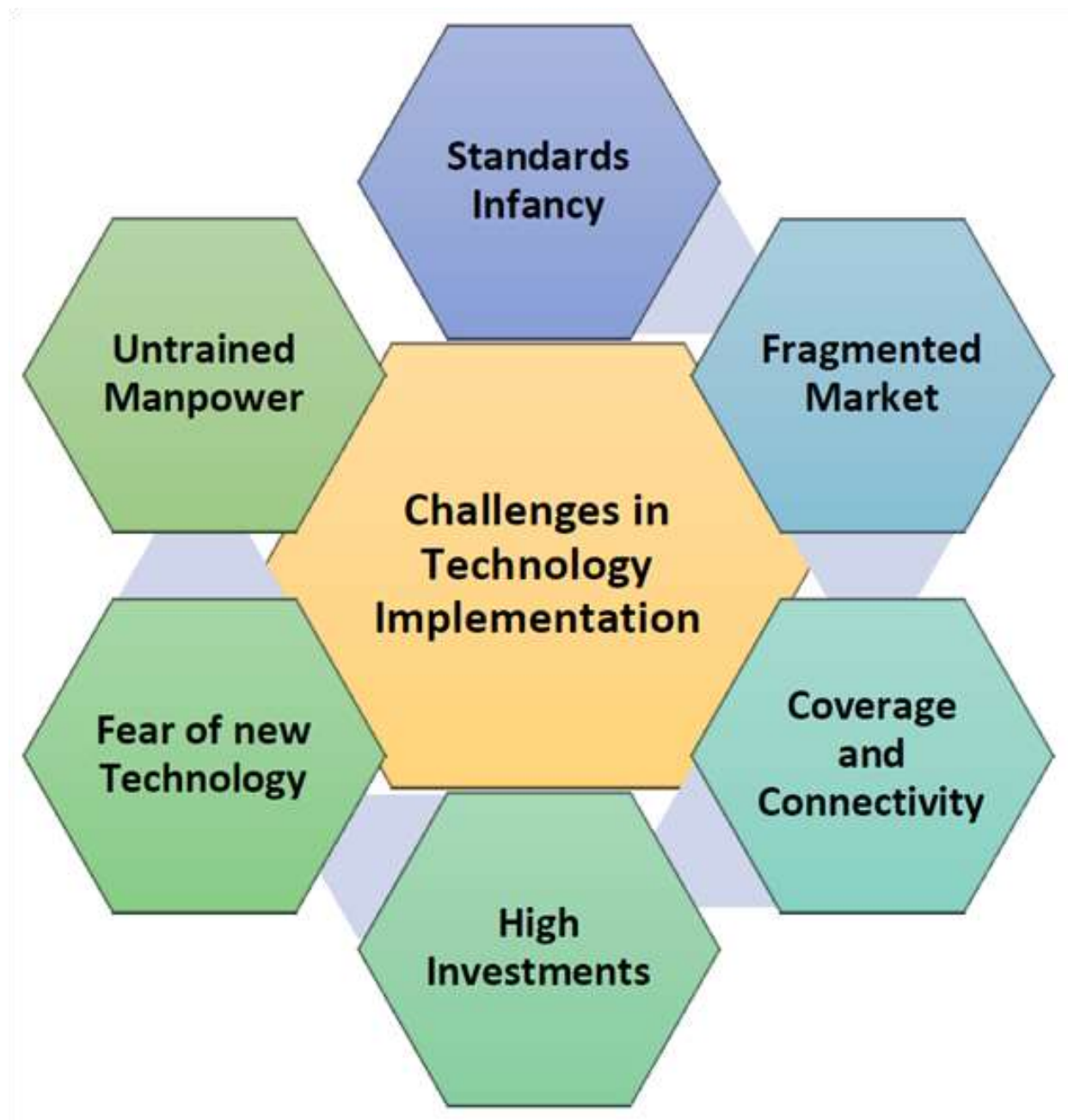

FIGURE 4: Challenges of IoT in agriculture [16]. 